\title{
BMJ Open Psychosocial factors and indoor environmental quality in respiratory symptom reports of pupils: a cross- sectional study in Finnish schools
}

\author{
Kateryna Savelieva (D) , ${ }^{1}$ Marko Elovainio, ${ }^{2}$ Jussi Lampi, ${ }^{3}$ Sari Ung-Lanki, ${ }^{3}$ \\ Juha Pekkanen ${ }^{1,3}$
}

To cite: Savelieva K,

Elovainio M, Lampi J, et al. Psychosocial factors and indoor environmental quality in respiratory symptom reports of pupils: a cross-sectional study in Finnish schools. BMJ Open 2020;10:e036873. doi:10.1136/ bmjopen-2020-036873

- Prepublication history and additional material for this paper are available online. To view these files, please visit the journal online (http://dx.doi. org/10.1136/bmjopen-2020036873).

Received 09 January 2020 Revised 29 May 2020 Accepted 26 June 2020

Check for updates

(C) Author(s) (or their employer(s)) 2020. Re-use permitted under CC BY-NC. No commercial re-use. See rights and permissions. Published by BMJ.

${ }^{1}$ Department of Public Health, Faculty of Medicine, University of Helsinki, Helsinki, Finland

${ }^{2}$ Department of Psychology and Logopedics, Faculty of Medicine, University of Helsinki, Helsinki, Finland

${ }^{3}$ Department of Health Security, Environmental Health Unit,

Finnish Institute for Health and Welfare, Kuopio, Pohjois-Savo, Finland

Correspondence to

Dr Kateryna Savelieva;

kateryna.savelieva@helsinki.fi

\section{ABSTRACT}

Objectives Poor indoor environmental quality (IEQ) in schools is related to higher respiratory symptoms of pupils, but little is known about the importance of other factors. This study examined the associations between different psychosocial factors and other pupils' individual and allergic characteristics, beyond school IEQ, and reporting of respiratory symptoms in pupil-administered and parentadministered questionnaires.

Setting All primary and secondary schools in two areas of Helsinki, Finland.

Participants Primary school pupils (grade $3-6, n=8775$, 99 school buildings) and secondary school pupils (grade 7-9, $n=3410,30$ school buildings) reported their respiratory symptoms, as well as psychosocial factors and individual characteristics. Parents of primary school pupils (grade 1-6, $n=3540,88$ school buildings) also filled in questionnaires, but the response rate was low $(20 \%$ in 2017 and $13 \%$ in 2018).

Main outcome measure Respiratory symptoms were reported in relation to the school environment and in general (without such relation) by pupils or parents. Results Worry about IEQ and low school satisfaction, and asthma and hay fever were related to higher reporting of respiratory symptoms in three samples. The variance between schools in respiratory symptoms was low (intraclass correlation $=0.6 \%-2.4 \%$ ). Psychosocial factors, especially worry about school's IEQ, explained more of the variance between schools in symptoms than IEQ among secondary school pupils and parents, but not among primary school pupils for symptoms in general. Worry about IEQ also modified the associations between IEQ and respiratory symptoms, but only in parental reports.

Conclusion In addition to IEQ, psychosocial factors and pupils' individual and allergic characteristics were related to higher reporting of respiratory symptoms in all three samples. Psychosocial factors explained more variance between schools than IEQ, although it was 2.4\% at most. Other factors beyond IEQ should be considered when interpreting symptom reporting in indoor air questionnaires.

\section{INTRODUCTION}

Consistent associations have been shown between indoor environmental quality (IEQ)
Strengths and limitations of this study

- A large-scale study including in total 135 school buildings and 15725 participants.

- Analyses were conducted in three different samples (primary school pupils, secondary school pupils and parents) and for symptoms reported in relation to the school environment and in general.

- Indoor environmental quality was evaluated by the same experts in all school buildings and not based on self-reports from pupils or parents.

- Respiratory symptoms were based solely on selfreports, and no objective measurements of pupils' health were available.

- Cross-sectional study design does not allow to determine the direction of the associations between psychosocial factors and respiratory symptoms.

problems in home and respiratory symptoms of children. ${ }^{1-3}$ Several studies have also shown that IEQ problems are common in schools and have adverse effects on pupils' performance and health. ${ }^{4-7}$ For example, moisture and mould damage, improper ventilation and unsatisfactory temperature conditions in schools are associated with increased reporting of respiratory symptoms among pupils. ${ }^{8-15}$ However, less is known about the role of other factors, such as psychosocial factors, beyond IEQ in reporting of respiratory symptoms among pupils in schools.

Psychosocial factors, along with buildingrelated factors, are related to perceived health and symptom reporting. ${ }^{16-18}$ Several studies in office buildings have shown that poor psychosocial work environment (characterised by high job demands, low work control, and low support at work), low satisfaction with the work environment, high stress, health-related worry and such personality trait as neuroticism are associated with increased symptom reporting. ${ }^{19-24}$ In school settings, the role of 
psychosocial factors in symptom reporting among pupils has received less attention. ${ }^{25}{ }^{26}$ The longitudinal study by Finell $e t a l^{25}$ found that increased socioemotional difficulties of pupils are related to higher reporting of indoor air-related symptoms (ie, stuffy nose, raspy voice, cough, dyspnoea and itchy and watering eyes). Another study by Nissilä $e t a t^{26}$ showed that worry about indoor air quality problems increased symptom reporting. However, no previous study has examined how a range of various psychosocial and individual characteristics, beyond school IEQ, are related to respiratory symptom reporting among pupils. It is also possible that pupils' reporting of symptoms differs between schools due to school IEQ or due to psychosocial characteristics of pupils (eg, worry and school satisfaction), suggesting potential clustering of schools. Previous studies on perceived indoor air quality have shown that both pupil-level and school-level psychosocial factors explained part of the variance between schools on perceived indoor air quality. ${ }^{27}$ However, it has not been addressed how much variance in symptom reporting between schools is explained by psychosocial, and individual and allergic characteristics of pupils in addition to school IEQ. This information could contribute to the use and interpretation of questionnaires on indoor air and related symptoms.

The indoor air questionnaires sometimes ask whether symptoms are related to a certain indoor environment or even get worse in a certain environment. ${ }^{28}$ It is difficult for some respondents to assess this, ${ }^{29}$ and symptoms that are attributed to a specific environment may also produce responses more related to this environment, ${ }^{26}$ although this has not been studied. We have previously found that the associations between school IEQ and pupils' symptoms were stronger in magnitude when symptoms were reported in relation to the school environment compared with symptoms reported without such relation. ${ }^{29}$ However, it has not been addressed whether the associations between psychosocial factors and symptom reporting differ when symptoms are asked in relation to being in school and when symptoms are experienced in general (ie, without relation to any specific environment). Based on previous studies, ${ }^{25}{ }^{26}$ it might be possible that pupils who are more worried about school IEQ, less satisfied with the school environment, or have higher neuroticism would report more symptoms, especially in relation to the school environment.

In this study, we assessed the associations between pupils' psychosocial factors, and individual and allergic characteristics, beyond IEQ, with respiratory symptoms reported by primary and secondary school pupils, as well as by parents of primary school pupils. We also compared how much variance between schools in respiratory symptoms is explained by IEQ, psychosocial factors, and individual and allergic characteristics. Finally, we examined whether the associations between psychosocial factors, and individual and allergic characteristics with respiratory symptoms differ when symptoms were reported in relation to the school environment and without such relation.

\section{METHODS}

\section{Study population}

Cross-sectional data came from the survey of IEQ and symptom reporting, conducted in all primary (grade 1-6) and secondary schools (grade 7-9) in Helsinki, Finland, in 2017-2018. The survey was conducted in 33 primary schools and 13 secondary schools during winter $2017^{30}$ and 43 primary schools and 23 secondary schools during winter $2018 .^{31}$ The majority of school buildings were built between 1950s and 1990s; most buildings have balanced mechanical ventilation, some have exhaust-only mechanical ventilation, and a few have natural (non-mechanical) ventilation. More information about schools selection can be found elsewhere. ${ }^{29}$

3-6 grade pupils in primary schools and 7-9 grade pupils in secondary schools participated in the survey (response rate for both primary and secondary school pupils was above $50 \%$, online supplemental table 1 ). The parents of primary school pupils were also invited to participate, yet the response rate was very low $(20 \%$ in 2017 and 13\% in 2018, online supplemental table 1); therefore, the results based on parental data should be interpreted with caution. In primary and secondary schools, pupils filled in the questionnaires in classrooms via the electronic form under the teacher supervision. Parents filled in the questionnaires through the online system and were instructed to answer the questions about symptoms and health conditions together with the child. Participation in the survey was voluntary, and parents could refuse the use of their children's information both for primary and secondary school pupils.

The data from 2017 and 2018 surveys were combined for this study. On exclusion the schools with special education and the school buildings in which there were less than 10 responses per building or missing expert evaluation of IEQ problems, the analytical samples comprised 8775 primary school pupils (99 school buildings), 3410 secondary school pupils (30 school buildings) and 3540 parents of primary school pupils (grades 1-6, 88 school buildings). The exclusion criteria are shown in online supplemental figure 1 .

\section{Patient and public involvement}

No patients or members of public were involved in the development of the research questions or the outcome measures, nor were they involved in developing plans for design or implementation of the study.

\section{Outcome measures}

Respiratory symptoms reported in general. Respiratory symptoms were assessed via the questionnaire developed for secondary school pupils and parents for primary school pupils, as well as via the simplified questionnaire for primary school pupils. The questionnaire for secondary school pupils included five questions on upper respiratory symptoms experienced during the last 4 weeks (ie, runny nose, stuffy nose, cough, hoarseness and sore throat); the questionnaire for primary school pupils 
comprised four questions on the respiratory symptoms experienced during the last 2 weeks (ie, runny or stuffy nose, cough, hoarseness and sore throat). Pictures of a child experiencing the symptom were included in the questionnaire for primary school pupils to help them better understand the questions. All items for secondary school pupils questionnaire had four response options (ie, 0 = 'never', 1 = 'sometimes', 2 = 'every week', and 3 = 'almost every day'), while items for primary school pupils questionnaire had three response options (ie, $0=$ 'never', $1=$ 'sometimes', $2=$ 'almost every day'). To focus on the more severe symptoms, each symptom item was first dichotomised $(0=$ 'never or sometimes' and $1=$ 'every week or almost every day' for secondary school pupils; 0 $=$ 'never', $1=$ 'sometimes or almost every day' for primary school pupils). Then, a respiratory symptom score was created and coded as ' 1 ' if a child reported having at least one of the symptoms included in the symptom score and ' 0 ' if a child reported no symptoms.

Respiratory symptoms related to the school environment. All survey respondents were also asked whether they think the above-mentioned respiratory symptoms as a group are related to the school environment. The question had three response options $(0=$ 'no/no symptoms', $1=$ 'yes', $9=$ 'I do not know'). In this study, only those respondents who reported having at least one symptom every week or almost every day and related the respiratory symptoms to the school environment were coded as ' 1 ', and the rest as ' 0 '. The proportions of pupils who did not know whether their respiratory symptoms were related to the school environment were the following: $35 \%$ for primary school pupils, $36 \%$ for secondary school pupils and $33 \%$ for parents of the primary school pupils.

\section{Indoor environmental quality}

The IEQ in all school buildings was assessed by the same experts who had a long work history with schools at the City of Helsinki before the questionnaire survey. One expert came from the Occupational Safety Section of the City of Helsinki and the two others from the Building Maintenance Section of the City of Helsinki. The assessment was based on all existing data from each school, and no special visits to the schools were done. In the course of several sessions, the experts rated all the school buildings by reaching a consensus concerning the relative rating of the school buildings using a building checklist with the following criteria: (1) moisture and mould damage, (2) insufficient ventilation, (3) unsatisfactory temperature conditions (too cold or too hot), (4) building structures with high risk of moisture damage, (5) strong smell of mould, (6) other strong smells, (7) extensive coating damage and emission due to moisture damage in concrete floor structures (most commonly refers to situations where adhesive or plasticiser of a polyvinyl chloride or similar floor reacts with an alkaline moisture of the concrete slab causing volatile organic compounds emissions), (8) mineral fibres in building or in the ventilation system, and (9) other significant impurities in the ventilation system. Item 1 was rated on the scale from 0 $=$ 'no damage' to $3=$ 'extensive damage and significant extent of repair', while items from 2 to 9 were rated on the scale $0=$ 'no', 1 = 'possible', 2 = 'yes'. The criteria for expert evaluation were based on the report by Finnish Institute of Occupational Health, ${ }^{32}$ which presents a comprehensive system for assessing indoor air problems at work according to Finnish legislation and guidelines. ${ }^{33}$ To validate the expert assessment of IEQ in schools, moisture and mould damage were also assessed in a subsample of 43 school buildings by two independent inspectors who visited the schools using mainly visual, non-intrusive observation. The inspectors used same grading as the experts and were blinded to the questionnaire results and the experts' ratings. A moderate correlation was found between moisture and mould damage rated by experts and by inspectors (Kendall's tau $=0.33, \mathrm{p}=0.023$ ); whereas the results from the concordance analysis demonstrated substantial agreement between the two ratings (weighted kappa $=69 \%){ }^{29}$

Several IEQ indicators were highly correlated; therefore, all school buildings were grouped into three classes of IEQ problems according to the results of the latent class analysis conducted earlier ${ }^{29}$ : (1) good IEQ $(n=62$ school buildings, $46 \%)$, (2) moderate IEQ ( $\mathrm{n}=54,40 \%)$ and (3) poor IEQ $(n=19,14 \%)$. We used these three classes of IEQ (good IEQ as a reference) in all statistical analyses in this study.

\section{Psychosocial factors}

All psychosocial factors, except personality traits, were measured with the same questions and scales in all three samples. Personality traits were reported only by primary and secondary school pupils.

Worry about indoor air quality was measured on individual level (reported by 3-9 grade pupils and parents of 1-6 grade pupils) and school level (reported by schools' principals) with the question 'How worried are you about the quality of indoor air in your school?' and rated on a 5-point Likert scale ( $1=$ "not worried at all about indoor air quality', 5 = 'worried a lot about indoor air quality').

Satisfaction with school environment was measured on individual level using four statements: 'It is nice being at school', 'I am doing well at school' (for secondary school pupils-'I feel drowned in schoolwork', reverse), 'Teachers encourage and support me' and 'Teachers treat us pupils fairly'. All the items were scored on a 5-point Likert scale ( 1 = 'always or often', 5 = 'rarely or never') and averaged to form one variable for overall satisfaction with school environment (1 stands for 'high satisfaction' and 5-for 'low satisfaction'). The reliability of the scale was good (Cronbach's alpha $=0.70)$.

Satisfaction with home environment was measured on individual level using one statement: 'It is nice being at home'. The responses were rated on a 5-point Likert scale ( $1=$ 'always or often', $5=$ 'rarely or never'). Because the variable was highly skewed, we categorised it in the 
following way: 0 = 'always or often', 1 = 'quite often', 2 = 'occasionally, quite rarely, and rarely or never'.

Whether a pupil has friends was also measured on individual level using one statement: 'I have friends with whom to spend time' and rated on a 5-point Likert scale $(1=$ 'always or often', $5=$ 'rarely or never'). Because the variable was skewed, it was categorised in the same way as satisfaction with home environment: $0=$ 'always or often', $1=$ 'quite often', 2 = 'occasionally, quite rarely, and rarely or never'.

Personality traits were self-reported by $3-6$ grade and 7-9 grade pupils using a 15 -item Big Five Inventory, ${ }^{34}$ that is, with three items per trait. Pupils were asked to rate on a 5 -point Likert scale ( $1=$ strongly agree to $5=$ strongly disagree) to what extent the following statements describe them. The sample statements included 'I am talkative' (Extraversion), 'I get nervous easily' (Neuroticism), 'I am original, I come up with new ideas' (Openness), 'I have a forgiving nature' (Agreeableness), and 'I do my job until the end' (Conscientiousness). The Cronbach's alpha values for Extraversion, Neuroticism, Openness, Agreeableness and Conscientiousness were 0.46, 0.56, 0.67, 0.48 , and 0.47 for primary school children and $0.71,0.60$, $0.76,0.33$ and 0.49 for secondary school pupils, respectively. These reliability values were from relatively low to low, but in line with those reported previously for 15-item Big Five Inventory. ${ }^{34} 35$

\section{Individual and allergic characteristics}

Individual characteristics included pupils' age, sex $(0=$ 'boys', 1 = 'girls'), and tobacco smoking. Smoking was coded as passive smoking for primary school pupils $(0=$ 'no one smokes', 1 = 'mother, father or another person in the household smokes') and as active smoking for secondary school pupils $(0=$ 'no', $1=$ 'yes'). Allergic characteristics comprised asthma, allergic rhinitis or hay fever, and atopic dermatitis experienced during the last 12 months which were self-reported by the survey participants (all coded as $0=$ 'no', $1=$ 'yes'). These individual and allergic characteristics were chosen because they are related to higher symptom reporting according to previous research. ${ }^{2321} 2428$ We also adjusted the analyses for attending the Swedish-speaking school $(0=$ 'no', $1=$ 'yes', school-level variable) to take into account the difference in questionnaires' languages.

\section{Statistical analyses}

We used a random-intercept multilevel logistic regression to assess the associations of IEQ problems (assessed on school level), psychosocial factors, and individual and allergic characteristics (assessed on pupil and school level) with respiratory symptom reporting of pupils (assessed on pupil level) using melogit command in Stata to take into account the hierarchical structure of the data (ie, pupils are nested within schools). First, we built a null model which included only the random effect of school building and no explanatory variables to examine how the pupil-reported respiratory symptoms differed between the school buildings. We estimated the intraclass correlation (ICC) in our model, which represents the proportion of observed variation in the outcome attributable to the effect of clustering. ${ }^{36}$ We also calculated the median OR (MOR) to quantify the effect of clustering; MOR is the median OR between the subject at a higher risk of the outcome and the subject at the lower risk of the outcome ${ }^{36}$ Second, we built several models to examine the associations between individual and allergic characteristics, psychosocial factors and school IEQ with respiratory symptom reporting, and to estimate variance explained in symptom reporting between schools. Model 0 included all individual characteristics as explanatory variables; model 1 included all individual and allergic characteristics and school IEQ; model 2 included all individual and allergic characteristics, as well as psychosocial factors; finally, model 3 included all individual and allergic characteristics, school IEQ and psychosocial factors. For each model, we estimated the ICC, MOR and the proportional change in cluster variation (PCV) to quantify the variation explained by the model. PCV was calculated as the proportion of the school variance in model adjusted for individual characteristics explained by adding (1) school IEQ (2) psychosocial factors, and (3) both school IEQ and psychosocial factors. All analyses were repeated with respiratory symptoms reported in relation to the school environment. All continuous variables (ie, age, worry about IEQ personality traits and satisfaction with school environment) were mean centred prior to analyses to facilitate the interpretation of the results. The respiratory symptom score reported in general and in relation to the school environment was used in the analyses as a binary variable and three classes of IEQ as an ordinal variable.

We also examined whether individual-level worry about IEQ modifies the associations between IEQ and symptom reporting by including a two-way interaction term to the multilevel model (ie, school IEQ $\times$ worry about IEQ on symptoms). Worry about IEQ was used as a dichotomised variable in this analysis $(0=$ "not worried at all or worried a bit', 1 = 'worried a lot, quite a lot, or to some extent').

As supplementary analyses, we examined the associations between psychosocial factors reported by primary school pupils (3-6 grades) and respiratory symptoms reported by parents of these pupils in the combined sample of parent-pupil pairs. The analyses were conducted in the original sample (complete cases, $n=1606$ ) and in the imputed sample $(n=8775)$. Multiple imputation under fully conditional specification was done, ${ }^{37}$ and the statistical analyses were conducted using the pooled estimates of 20 imputed data sets.

All statistical analyses were conducting using Stata V.15. ${ }^{38}$

\section{RESULTS}

\section{Characteristics of the sample}

The mean age of 3-6 grade pupils was 10.7 ( $\mathrm{SD}=1.22)$, ranged from 7 to 14 years, and of 7-9 grade pupils 
$14.2(\mathrm{SD}=0.95)$, ranged $13-17$, respectively. In parental reports, the mean age of 1-6-grade pupils was 9.6 $(\mathrm{SD}=1.72)$, ranged from 6 to 14 years. Half of the pupils in all samples were women (52\%). The prevalence of respiratory symptoms reported in general (in relation to the school environment) were the following: $21.2 \%(7.1 \%)$ for primary school pupils, $17.1 \%(7.2 \%)$ for secondary school pupils, and $12.5 \%$ (4.6\%) for 1-6 grade pupils in parental reports. The mean level of worry about IEQ was $1.75(\mathrm{SD}=0.95)$ when reported by primary school pupils, $2.21(\mathrm{SD}=1.11)$ when reported by secondary school pupils and $2.31(\mathrm{SD}=1.13)$ in parental reports for $1-6$ grade pupils (table 1).

\section{Associations of psychosocial factors, individual and allergic characteristics, beyond IEQ, with symptom reporting}

Older age, female sex, passive smoking at home, asthma, hay fever and atopic dermatitis were related to higher respiratory symptoms reported in general among primary school pupils; whereas attending Swedish-speaking school (school-level variable) was not associated with respiratory symptoms (table 2). Among secondary school pupils, the associations were the same as among primary school pupils, except there was no relation between own smoking and respiratory symptoms. In parental reports, only passive smoking at home, asthma and hay fever were associated with increased respiratory symptoms. These associations were similar when symptoms were reported in relation to the school environment, but slightly stronger in magnitude (table 2).

Among psychosocial factors, worry about school IEQ was most consistently associated with higher reporting of respiratory symptoms in all three samples when the model was adjusted for individual characteristics, IEQ, and other psychosocial factors (tables 3-5). The associations between worry about IEQ and symptoms were much stronger in magnitude when symptoms were reported in relation to the school environment compared with symptoms reported in general. Dose-response associations between worry and respiratory symptoms were observed (online supplemental table 2). School principal-reported worry about IEQ was associated with higher symptom reporting, but only when pupilreported or parent-reported worry was not included to the models: ORs for primary school pupils were 1.10 (1.02 to 1.19 ) and 1.22 (1.08 to 1.38 ; reported in general and in relation to the school environment, respectively); ORs for secondary school pupils were 1.21 (1.05 to 1.40) and 1.65 (1.37 to 1.99), respectively; ORs for parents were 1.37 (1.16 to 1.61 ) and 2.08 (1.62 to 2.68), respectively. When pupil-reported or parent-reported worry was included to the models, the associations between school principal-reported worry and respiratory symptoms were attenuated (tables 3-5). To continue, lower school satisfaction was also associated with increased respiratory symptoms when reported in general in all three samples (tables 3-5). Among personality traits, higher neuroticism and lower conscientiousness were related to increased respiratory symptom reporting both in primary and secondary school pupils' reports (there were no measures of pupils' personality in parental reports; tables 3-4).

In the combined sample of parent-child pairs, pupilreported worry was related to higher respiratory symptoms reported by parents for their children both in relation to the school environment and without such relation; school principal-reported worry was also related to respiratory symptoms, but only when reported in relation to the school environment (online supplemental table $3)$. The results in the imputed and original sample were largely the same.

As we have previously shown, ${ }^{29}$ moderate and poor IEQ were associated with higher symptom reporting when adjusting for the individual and allergic characteristics. However, in the model additionally adjusted for psychosocial factors, the associations between IEQ and symptoms remained significant only in primary school pupils' reports (tables 3-5).

\section{Variance between schools in respiratory symptoms}

Based on the results from the null model including random intercept, the variance between schools was statistically significant but very low for respiratory symptoms reported in general (ICC $=0.6 \%, \mathrm{p}=0.010$ for primary school pupils; ICC $=1.4 \%, \mathrm{p}<0.001$ for secondary school pupils; and ICC $=1.3 \%, \mathrm{p}=0.016$ for parents of primary school pupils) and slightly higher for respiratory symptoms reported in relation to the school environment (ICC $=0.6 \%, \mathrm{p}=0.013$ for primary school pupils; ICC $=2.4 \%, \mathrm{p}<0.001$ for secondary school pupils; ICC $=2.2 \%, \mathrm{p}<0.001$ for parents of primary school pupils). Psychosocial factors, especially worry about IEQ, explained more of the variance between schools in respiratory symptoms than IEQ in the reports by secondary school pupils and parents (online supplemental table 4). Individual and allergic characteristics explained much less variance between schools in symptom reporting (online supplemental table 5).

\section{Interactions between IEQ and worry about IEQ on symptom reporting}

We found no interactions between IEQ and pupil-reported worry about school's IEQ on respiratory symptoms both in primary and secondary school pupils' reports. However, there was a statistically significant interaction term between poor IEQ and worry about schools' IEQ on respiratory symptoms in parental reports $(\mathrm{p}=0.004)$. Poor IEQ was associated with increased respiratory symptoms only among those parents who were worried about IEQ in schools (OR=1.46, 95\% CI (1.04 to 2.05)) but not among those who were not worried about IEQ in schools $(\mathrm{OR}=0.34,95 \%$ CI (0.34 to 1.09$)$ ). Online supplemental figure 2 shows the prevalence of respiratory symptoms by IEQ and parental worry. 


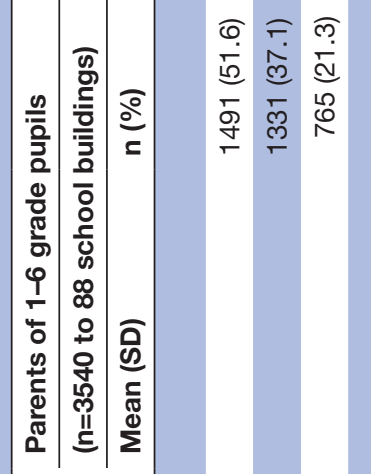

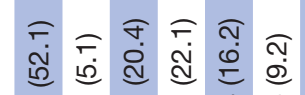

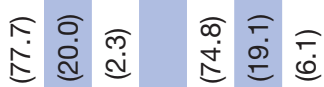

กิ

品

炙

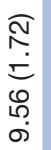

은

ᄃ 巳 巳

ल เू

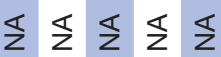

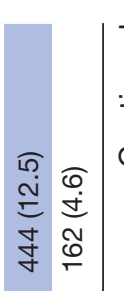

Љू ल्ल

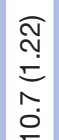

อ 巳 巳

ㄴ.?

लू

¿ 巳 e 巳 é

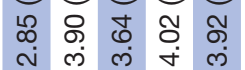


This study shows that in addition to IEQ psychosocial factors and individual and allergic characteristics are related to higher reporting of respiratory symptoms among both primary and secondary school pupils, as well as among parents who reported symptoms for their children. The associations between individual and allergic characteristics and respiratory symptoms were slightly stronger when symptoms were reported in relation to the school environment. Among psychosocial factors, only associations with worry about school IEQ became substantially stronger when symptoms were reported in relation to the school environment; whereas the associations with other psychosocial factors varied. We also found that psychosocial factors explained more of the variance between schools in respiratory symptoms than IEQ, especially in the reports by secondary school pupils and parents, but not among primary school pupils. However, the variance between schools in respiratory symptoms was low $(0.6 \%-2.4 \%)$ indicating that school buildings' characteristics have only minor effects on pupils' symptom reporting, and that the bigger share of variance in symptom reporting is explained by individual differences between pupils.

Among psychosocial factors, worry about school IEQ was consistently associated with higher respiratory symptom reporting in all three main samples, as well as in the combined sample of parent-child pairs where children reported psychosocial factors themselves and parents reported symptoms for their children. In line with previous studies ${ }^{26}$ showing that parents worried about school IEQ reported their children having symptoms more often than non-worried parents, we found that also pupils who were worried about school IEQ tend to report more respiratory symptoms independently of their individual and allergic characteristics, other psychosocial factors, and school IEQ. One possible explanation for this is that worries about health threats may change the way people perceive and interpret somatic information. ${ }^{39}$ Worries create symptom expectations and cause selective attention to bodily process, which has been shown to increase the number of symptom reports. ${ }^{39}$ To continue, worry was related to higher symptom reporting regardless of the school IEQ in pupils' reports, and only in parental data we found a significant interaction between school IEQ and worry about school IEQ on respiratory symptom reporting. In schools with poor IEQ parents who were worried about school IEQ reported more symptoms for their children than not worried parents. Although it has been suggested that worry might act as a potential explanatory variable on the pathway between school IEQ and symptom reporting, ${ }^{26}$ we cannot eliminate the possibility that pupils experience more symptoms in schools with poor IEQ which in turn induces more worries. Also, findings in parental data should be interpreted with caution due to the low response rate of parents (less than 20\%) and possible self-selection bias. 


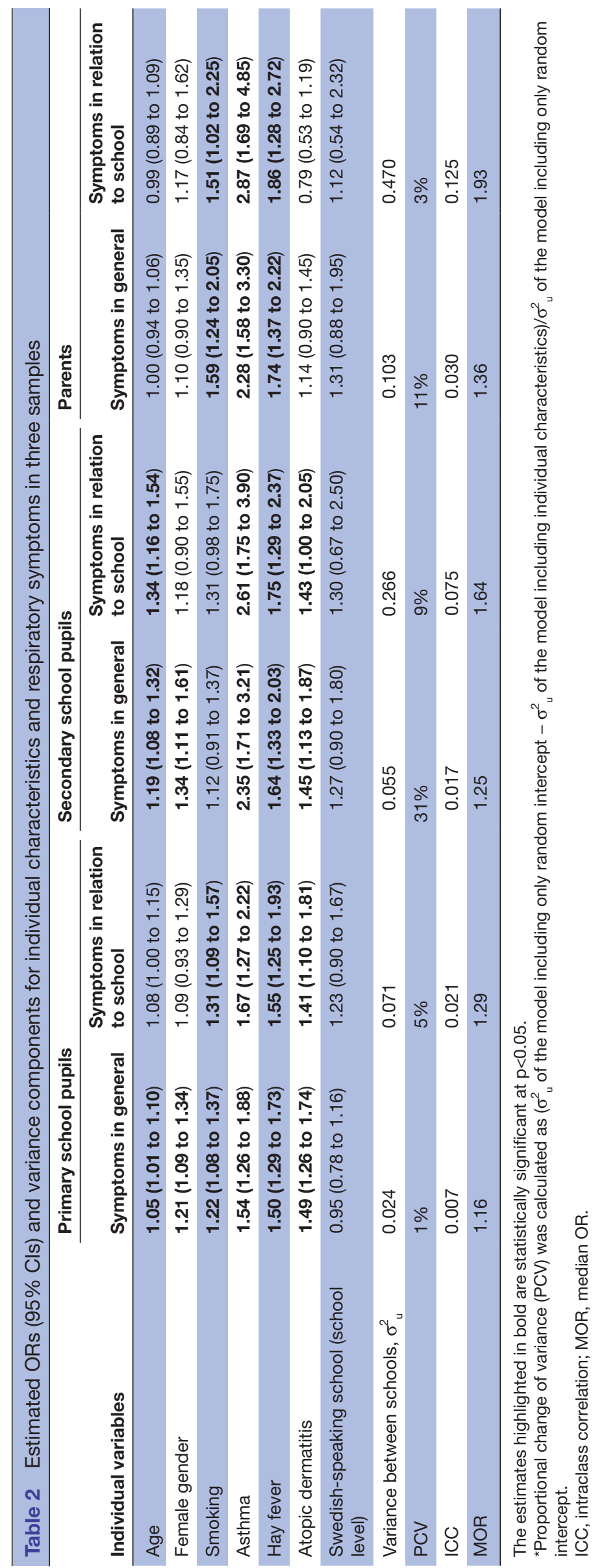




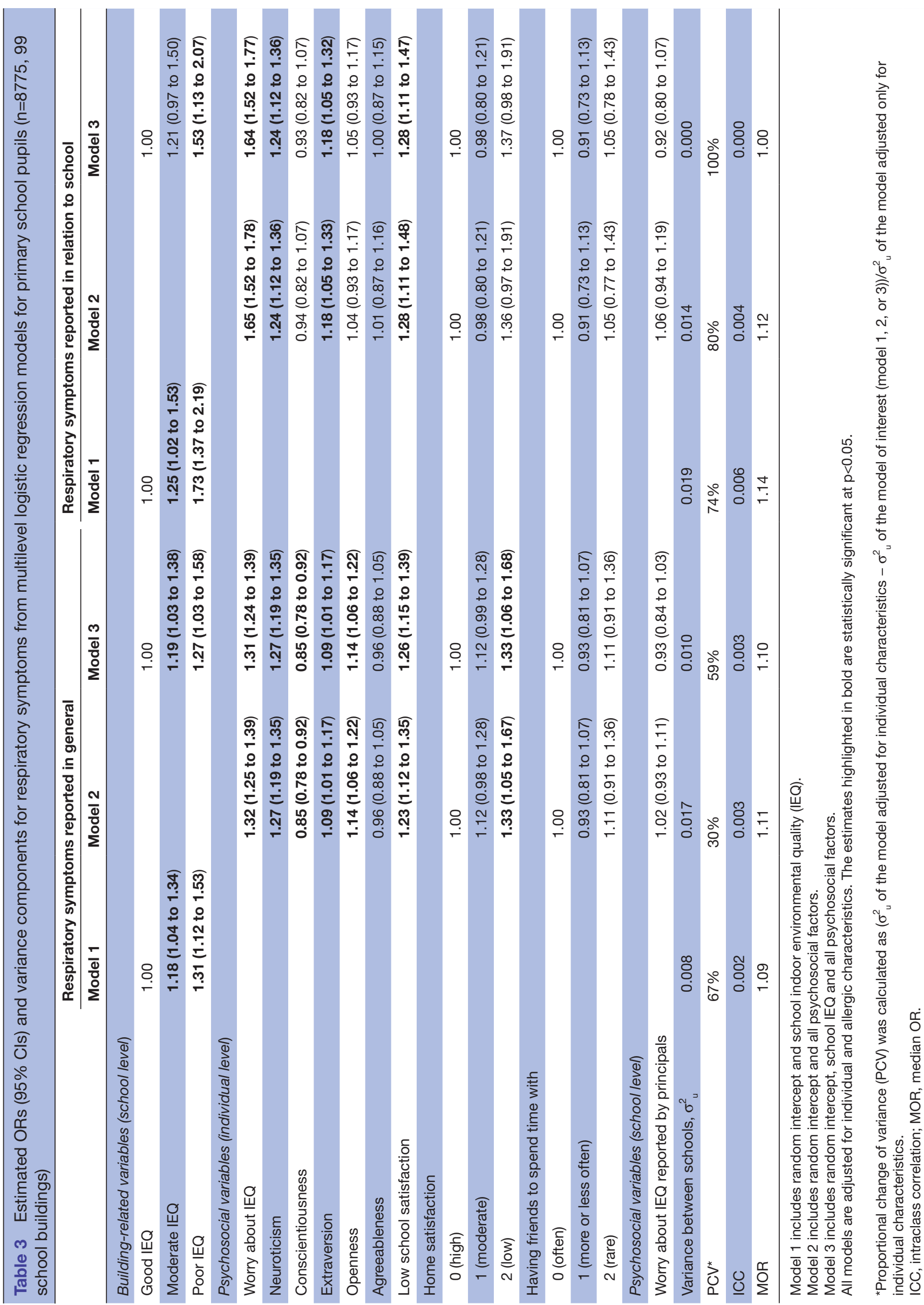




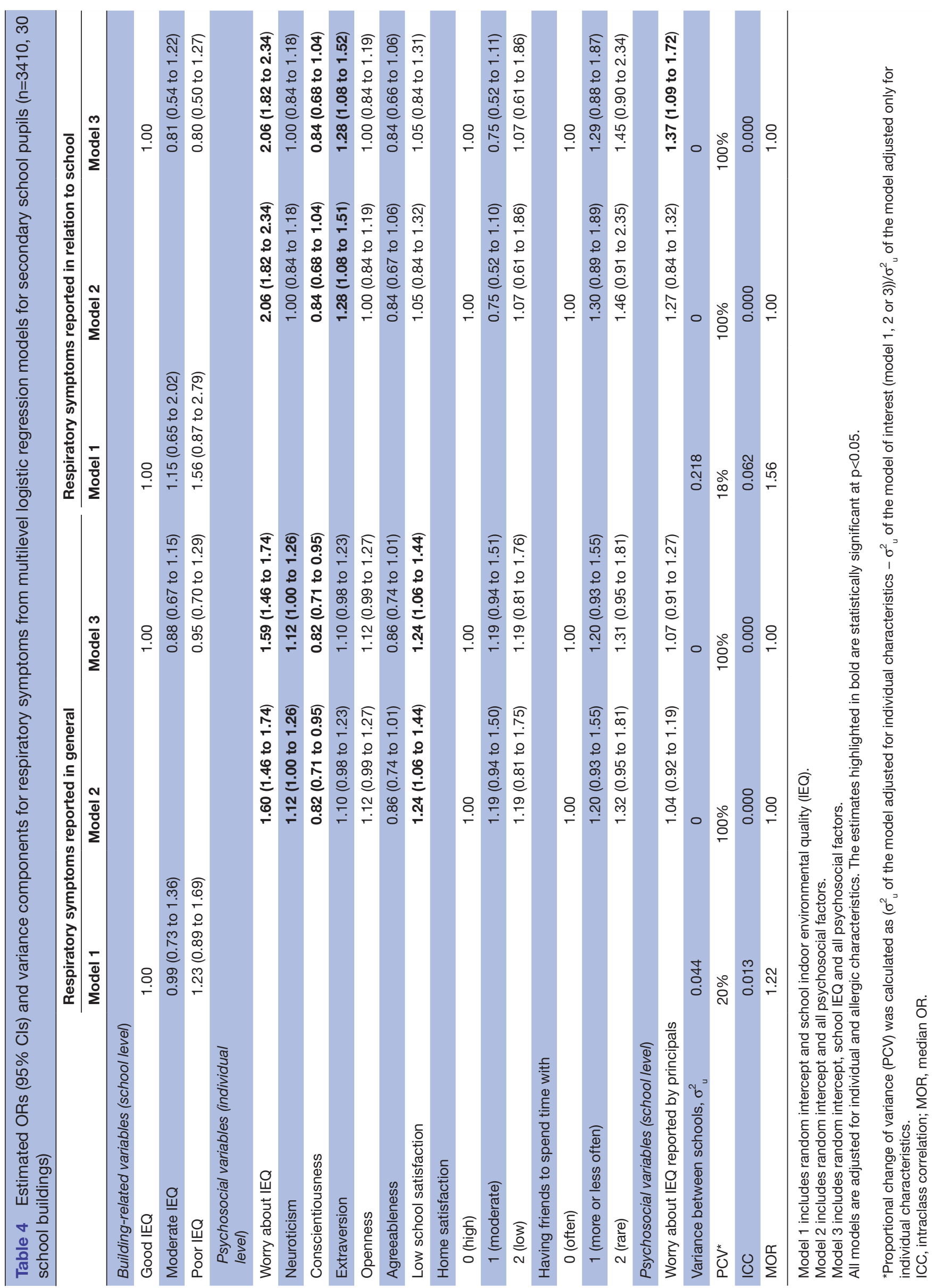




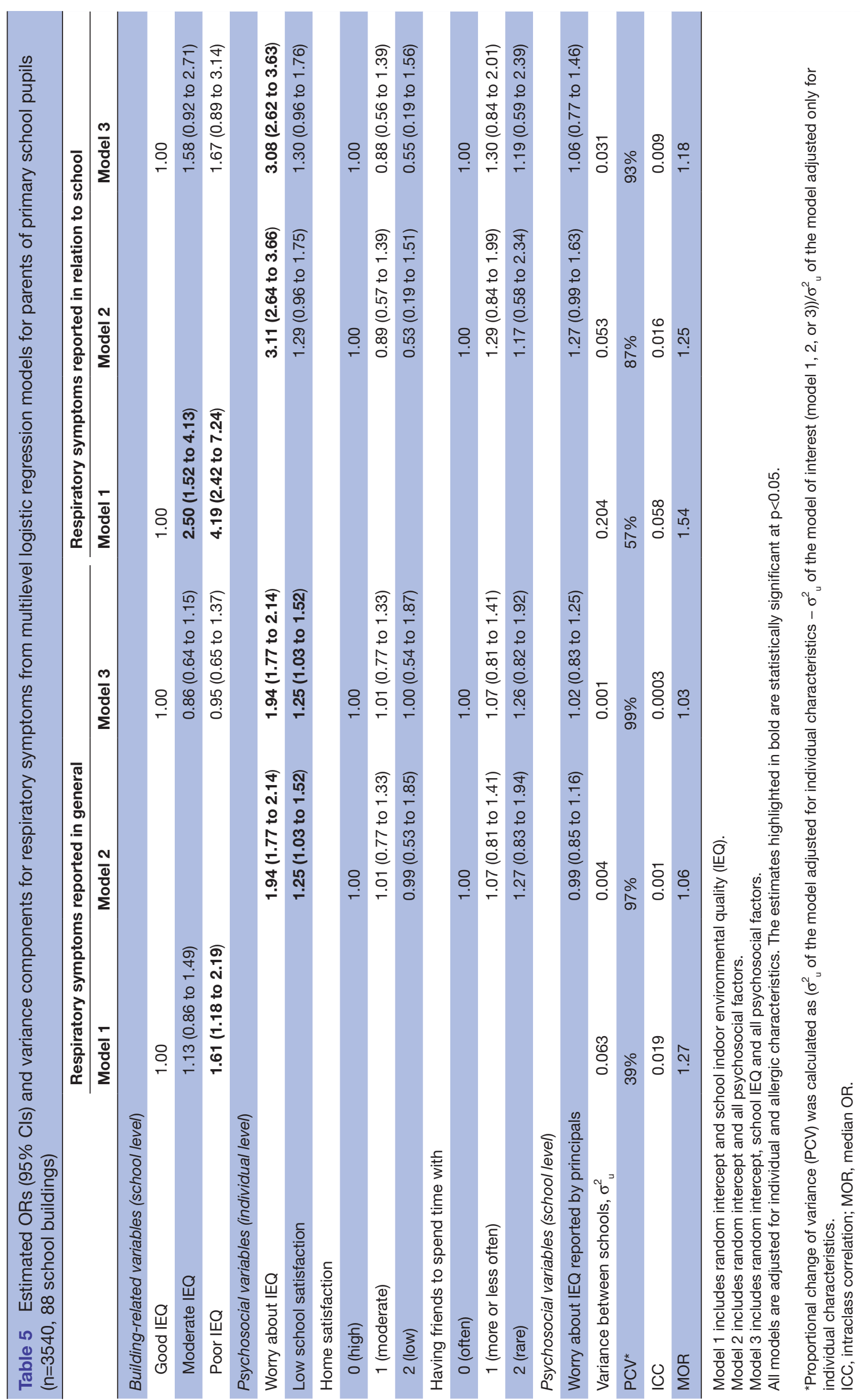


Other psychosocial factors that were associated with increased respiratory symptom reporting were low school satisfaction and personality traits. Findings from previous studies in office settings show that low job satisfaction and poor psychosocial work environment (eg, work overload, a lack of possibilities to control one's work situation, lack of social support, and poor interpersonal relationships) are associated with increased symptom reporting. ${ }^{16}$ 19-22 Among personality traits, higher neuroticism, which is characterised by a tendency to experience negative emotional states, was associated with increased respiratory symptom reporting in the present study. This accords with previous studies on high negative affectivity (a mood-related disposition similar to neuroticism) which is known to correlate with virtually all measures of symptoms. ${ }^{20} 40$ One line of explanations suggests that attentional processes and biases in the interpretation of bodily sensations may contribute to the relationship between neuroticism and increased symptom reporting. ${ }^{241}$ Another line of explanations is that people with high neuroticism have a higher sensitivity to negative experiences and poorer abilities in adapting to difficult situations, ${ }^{42}{ }^{43}$ which results in higher psychosocial stress leading, for example, to elevated blood pressure, increased migraines, and neck pains. ${ }^{44}$ Alternative explanations are also possible suggesting that health problems can cause distress and lead to personality changes (such as higher neuroticism) which, in turn, are related to higher symptom complaints. ${ }^{41}$

As for individual and allergic characteristics, we found consistent associations between asthma and allergic rhinitis with higher reporting of respiratory symptoms in all three samples. We also found that passive smoking at home was associated with increased respiratory symptoms in primary school pupils and parents, but not among secondary school pupils. This is extensively supported by previous research. ${ }^{23212428}$ In line with previous studies showing that women tend to report indoor air problems and symptoms more often than men, ${ }^{21} 284546$ we found that female sex was associated with higher respiratory symptom reporting among pupils. It has been suggested that males and females rely on different sources of information to interpret bodily states, and females are particularly sensitive to external environmental cues. ${ }^{24}$ Although speculative, this could partly explain the findings that women consistently report greater symptom levels in, for example, sick building syndrome or multiple chemical sensitivity. ${ }^{24}$

This study has some limitations which should be acknowledged. First, as we have discussed earlier in length, ${ }^{26}$ a cross-sectional design of this study does not allow to determine the direction of the associations between psychosocial factors, especially worry, and respiratory symptoms: we cannot state whether it is psychosocial factors that increases respiratory symptom reporting or whether experiencing symptoms induces psychosocial factors. Therefore, further studies with prospective study design are needed to investigate this issue. Second, respiratory symptoms were based on self-reports, and no objective measurements of pupils' health were available. To continue, there were also some differences in the questionnaires developed for primary school pupils and for secondary school pupils to assess respiratory symptoms: the former comprised fewer questions on symptoms, questions had one less response category, and the time period used was shorter, as compared with the latter. Finally, although the strength of the study is that IEQ were expert evaluated and not based on the reports from pupils or parents, neither specific measures of IEQ (eg, $\mathrm{CO}_{2}, \mathrm{PM} 2.5$ ) nor special visits to the school buildings were done, as described earlier. ${ }^{29}$ The expert evaluation of IEQ was done before the questionnaire survey, but we cannot eliminate the possibility that a higher number of symptom complaints in certain schools could have affected expert assessment of IEQ.

\section{CONCLUSION}

In conclusion, this study shows that psychosocial factors, and individual and allergic characteristics, in addition to school IEQ, were related to higher reporting of respiratory symptoms in pupil-administered and parentadministered questionnaires. These associations were somewhat stronger when symptoms were reported in relation to the school environment compared with being reported without such relation. Psychosocial factors also explained more of the variance between schools in symptom reporting than IEQ, although the overall variance in symptom reporting between schools was very low. These findings suggest that the role of other factors beyond IEQ should also be considered when interpreting symptom reporting in indoor air questionnaires.

Acknowledgements The authors thank the city of Helsinki for making this study possible and all the pupils and parents for filling in the questionnaires.

Contributors KS was involved in conceptualisation of the study, analysed the data, interpreted the results and drafted the manuscript. ME was involved in conceptualisation of the study, contributed to interpretation of the results and editing the manuscript. JL collected the data, contributed to interpretation of the results and editing the manuscript. SU-L collected the data and contributed to interpretation of the results. JP is the principal investigator of the study and coordinator of the data collection, conceptualised the study and contributed to interpretation of the results and editing the manuscript. All authors read and approved the final manuscript.

Funding This research was funded by the Juho Vainio Foundation, the Yrjö Jahnsson Foundation (grant 6988) and Ministry of Social Affairs and Health, Finland.

Competing interests None declared.

Patient consent for publication Not required.

Ethics approval The research plans were approved by the Institutional Review Board of the National Institute for Health and Welfare (THL), Finland (THL/1370/6.02.01/2016). Participation in the survey was voluntary, and parents could refuse the use of their children's information in the survey.

Provenance and peer review Not commissioned; externally peer reviewed.

Data availability statement Data are available upon reasonable request. The datasets analysed during the current study are not publicly available due to reasons of confidentiality, but are available from the corresponding author on reasonable request, after approval by the data protection authorities.

Supplemental material This content has been supplied by the author(s). It has not been vetted by BMJ Publishing Group Limited (BMJ) and may not have been 
peer-reviewed. Any opinions or recommendations discussed are solely those of the author(s) and are not endorsed by BMJ. BMJ disclaims all liability and responsibility arising from any reliance placed on the content. Where the content includes any translated material, BMJ does not warrant the accuracy and reliability of the translations (including but not limited to local regulations, clinical guidelines, terminology, drug names and drug dosages), and is not responsible for any error and/or omissions arising from translation and adaptation or otherwise.

Open access This is an open access article distributed in accordance with the Creative Commons Attribution Non Commercial (CC BY-NC 4.0) license, which permits others to distribute, remix, adapt, build upon this work non-commercially, and license their derivative works on different terms, provided the original work is properly cited, appropriate credit is given, any changes made indicated, and the use is non-commercial. See: http://creativecommons.org/licenses/by-nc/4.0/.

\section{ORCID iD}

Kateryna Savelieva http://orcid.org/0000-0002-4662-9707

\section{REFERENCES}

1 WHO. Who guidelines for indoor air quality: dampness and mould 2009.

2 Mendell MJ, Mirer AG, Cheung K, et al. Respiratory and allergic health effects of dampness, mold, and dampness-related agents: a review of the epidemiologic evidence. Environ Health Perspect 2011:119:748-56.

3 Fisk WJ, Eliseeva EA, Mendell MJ. Association of residential dampness and mold with respiratory tract infections and bronchitis: a meta-analysis. Environ Health 2010;9:72.

4 Haverinen-Shaughnessy U, Borras-Santos A, Turunen M, et al. Occurrence of moisture problems in schools in three countries from different climatic regions of Europe based on questionnaires and building inspections - the HITEA study. Indoor Air 2012;22:457-66.

5 Fisk WJ. The ventilation problem in schools: literature review. Indoor Air 2017;27:1039-51.

6 Mendell MJ, Heath GA. Do indoor pollutants and thermal conditions in schools influence student performance? A critical review of the literature. Indoor Air 2005;15:27-52.

7 Fisk WJ, Chan WR, Johnson AL. Does dampness and mold in schools affect health? results of a meta-analysis. Indoor Air 2019;29:895-902.

8 Borràs-Santos $\mathrm{A}$, Jacobs $\mathrm{JH}$, Täubel M, et al. Dampness and mould in schools and respiratory symptoms in children: the HITEA study. Occup Environ Med 2013;70:681-7.

9 Jacobs J, Borràs-Santos A, Krop E, et al. Dampness, bacterial and fungal components in dust in primary schools and respiratory health in schoolchildren across Europe. Occup Environ Med 2014;71:704-12.

10 Taskinen T, Meklin T, Nousiainen M, et al. Moisture and mould problems in schools and respiratory manifestations in schoolchildren: clinical and skin test findings. Acta Paediatr 1997;86:1181-7.

11 Toyinbo O, Matilainen M, Turunen M, et al. Modeling associations between principals' reported indoor environmental quality and students' self-reported respiratory health outcomes using glmM and ZIP models. Int J Environ Res Public Health 2016;13:385.

12 Turunen M, Toyinbo O, Putus T, et al. Indoor environmental quality in school buildings, and the health and wellbeing of students. Int J Hyg Environ Health 2014:217:733-9.

13 Meklin T, Potus T, Pekkanen J, et al. Effects of moisture-damage repairs on microbial exposure and symptoms in schoolchildren. Indoor Air 2005;15:40-7.

14 Putus T, Tuomainen A, Rautiala S. Chemical and microbial exposures in a school building: adverse health effects in children. Arch Environ Health 2004;59:194-201.

15 Haverinen-Shaughnessy U, Shaughnessy RJ, Cole EC, et al. An assessment of indoor environmental quality in schools and its association with health and performance. Build Environ 2015;93:35-40.

16 Lahtinen M, Sundman-Digert C, Reijula K. Psychosocial work environment and indoor air problems: a questionnaire as a means of problem diagnosis. Occup Environ Med 2004;61:143-9.

17 Norbäck D. An update on sick building syndrome. Curr Opin Allergy Clin Immunol 2009;9:55-9.

18 Carrer P, Wolkoff P. Assessment of indoor air quality problems in office-like environments: role of occupational health services. Int J Environ Res Public Health 2018;15:741.
19 Eriksson N, Hoog J, Stenberg B, et al. Psychosocial Factors and the "Sick Building-Syndrome". A case-referent study. Indoor Air 1996;6:101-10.

20 Kinman G, Griffin M. Psychosocial factors and gender as predictors of symptoms associated with sick building syndrome. Stress Heal 2008;24:165-71.

21 Runeson R, Wahlstedt K, Wieslander G, et al. Personal and psychosocial factors and symptoms compatible with sick building syndrome in the Swedish workforce. Indoor Air 2006;16:445-53.

22 Marmot AF, Eley J, Stafford M, et al. Building health: an epidemiological study of "sick building syndrome" in the Whitehall II study. Occup Environ Med 2006;63:283-9.

23 Lu C-Y, Tsai M-C, Muo C-H, et al. Personal, psychosocial and environmental factors related to sick building syndrome in official employees of Taiwan. Int J Environ Res Public Health 2017;15:7.

24 Pennebaker JW. Psychological factors influencing the reporting of physical symptoms. in the science of self-report. 2000:299-315.

25 Finell E, Tolvanen A, Pekkanen J, et al. Psychosocial problems, indoor Air-Related symptoms, and perceived indoor air quality among students in schools without indoor air problems: a longitudinal study. Int J Environ Res Public Health 2018;15:1497.

26 Nissilä J-J, Savelieva K, Lampi J, et al. Parental worry about indoor air quality and student symptom reporting in primary schools with or without indoor air quality problems. Indoor Air 2019;29:865-73.

27 Finell E, Haverinen-Shaughnessy U, Tolvanen A, et al. The associations of indoor environment and psychosocial factors on the subjective evaluation of indoor air quality among lower secondary school students: a multilevel analysis. Indoor Air 2017;27:329-37.

28 Reijula K, Sundman-Digert C. Assessment of indoor air problems at work with a questionnaire. Occup Environ Med 2004;61:33-8.

29 Savelieva K, Marttila T, Lampi J, et al. Associations between indoor environmental quality in schools and symptom reporting in pupiladministered questionnaires. Environ Health 2019;18:115.

30 Lampi J, Ung-Lanki S, Pekkanen J. Oppilaiden Sisäilmakyselyn Kehittämishanke Helsingissä - Tutkimusseloste 2017. (In Finnish Project on developing a new indoor air questionnaire for pupils in Helsinki - Report 2017

31 Lampi J, Ung-Lanki S, Pekkanen J. Oppilaiden Sisäilmakyselyn Kehittämishanke Helsingissä - Tutkimusseloste 2018. (In Finnish Project on developing a new indoor air questionnaire for pupils in Helsinki - Report 2018.

32 Lappalainen S, Reijula K, Tähtinen K, et al. Ohje työpaikkojen sisäilmasto-ongelmien selvittämiseen. (in Finnish - guide for solving indoor-air problems at work). Työterveyslaitos 2016.

33 Tähtinen K, Lappalainen S, Karvala K, et al. Association between four-level categorisation of indoor exposure and perceived indoor air quality. Int J Environ Res Public Health 2018;15:679.

34 Lang FR, John D, Lüdtke O, et al. Short assessment of the big five: robust across survey methods except telephone interviewing. Behav Res Methods 2011;43:548-67.

35 Leikas S, Salmela-Aro K. Personality trait changes among young Finns: the role of life events and transitions. J Pers 2015;83:117-26.

36 Austin PC, Merlo J. Intermediate and advanced topics in multilevel logistic regression analysis. Stat Med 2017;36:3257-77.

37 Van Buuren S. Flexible imputation of missing data. CRC press, 2018.

38 StataCorp. Stata statistical software: release 152017.

39 Rief W, Broadbent E. Explaining medically unexplained symptomsmodels and mechanisms. Clin Psychol Rev 2007;27:821-41.

40 Gomzi M, Bobic J, Radosevic-Vidacek B, et al. Sick building syndrome: psychological, somatic, and environmental determinants. Arch Environ Occup Health 2007;62:147-55.

41 Watson D, Pennebaker JW. Health complaints, stress, and distress: exploring the central role of negative affectivity. Psychol Rev 1989:96:234-54.

42 Watson D, Clark LA. On traits and temperament: general and specific factors of emotional experience and their relation to the five-factor model. J Pers 1992;60:441-76.

43 Watson D, Hubbard B. Adaptational style and dispositional structure: coping in the context of the Five-Factor model. J Pers 1996;64:737-74.

44 Rosmalen JGM, Neeleman J, Gans ROB, et al. The association between neuroticism and self-reported common somatic symptoms in a population cohort. J Psychosom Res 2007;62:305-11.

45 Magnavita N. Work-Related symptoms in indoor environments: a puzzling problem for the occupational physician. Int Arch Occup Environ Health 2015;88:185-96.

46 Brasche S, Bullinger M, Morfeld M, et al. Why do women suffer from sick building syndrome more often than men?--subjective higher sensitivity versus objective causes. Indoor Air 2001;11:217-22. 